\title{
World Heritage Cultural Landscapes: An Old or a New Concept for China?*
}

\author{
Feng Han \\ College of Architecture and Urban Planning, Tongji University, Shanghai, China \\ Email: franhanf@qq.com
}

\begin{abstract}
The term 'cultural landscape' has many different meanings for different people throughout the world. It has been widely circulated since the international recognition of cultural landscapes extended to World Heritage prominence in 1992 with three categories of cultural landscapes of outstanding universal value defined as the 'combined works of nature and of man'. However, the application of World Heritage Cultural Landscapes (WHCLs) encountered difficulties in China. This paper reviews the history of nature-related World Heritage conservation in the country, examines the cross-cultural confusion of World Heritage practice from Chinese traditional cultural perspective of culture and nature relationship to address to the international bewilderment about China's two-decade absence from WHCLs. The paper also reviews the efforts taken by China to dispel the conceptual confusion, what has been inspired by and contributed to the WHCLs in the recent years. Finally, the paper examines what China and WHCLs can mutually benefit from each other based on the common concerns of sustainable development and harmonious human-nature relationship in the future.
\end{abstract}

KEYWORDS World Heritage, cultural landscape, China, Historic Urban Landscape, rural landscape

Received August 28, 2018; accepted September 6, 2018.

\section{Introduction}

Cultural landscape is a Western concept in the field of cultural geography. Sauer (1925) defined it as 'the cultural landscape is fashioned from a natural landscape by a cultural group. Culture is the agent, the natural area the medium, the cultural landscape is the result'. The core of cultural landscape is to detect and interpret the generation, form, meaning and value of landscapes underpinned by culture changing through time. The mutual interaction and construction between humankind and nature forms the landscape. However, without its practice in the World Heritage fields, the term of 'cultural landscape' would have been locked up in the field of geographical studies and would not come into public awareness in China.

The World Heritage Committee adopted guidelines concerning the inclusion of cultural landscapes in the World Heritage List at its $16^{\text {th }}$ session. In 1992, UNESCO's Convention on the Protection of Natural and Cultural World Heritage Sites (hereinafter referred to as the Convention)

* Supported by the National Key Research and Development Program of China (2016YFC0503308). became the first international legal instrument to recognise and protect cultural landscapes (Rössler 2003). Defined as the 'combined works of nature and of man', the World Heritage Cultural Landscapes (WHCLs) are at the interface between nature and culture, tangible and intangible heritage, biological and cultural diversity-they represent a closely woven net of relationships, the essence of culture and people's identity (Rössler 2006). WHCLs not only provided a new category for international heritage conservation, but more importantly, they provided a holistic approach and an evolving world view of values.

As a flagship project of UNESCO with 25 years of development, WHCLs are now at the forefront of heritage conservation and sustainable development. However, it is just at the beginning of rise in China. In the State's World Heritage Tentative List, cultural landscape categories have not been systematically identified and their values have not been adequately interpreted yet. To date, China has 53 inscribed properties, ranking second in the world in number, but it has only 5 of the 106 WHCLs in the world (UNESCO 2018a). This indicates that the conservation of 
cultural landscapes is still at the primary stage in China. This situation is not consistent with the international community's respect, recognition and expectation of Chinese cultural landscapes.

What would now be recognised as cultural landscapes, deliberately expressing a relationship between nature and humans, were created in China in the first millennium $\mathrm{AD}$ (Fowler 2003a, 46).

China, a country that inspired WHCLs by its representative Eastern philosophy of 'Oneness with Nature' and is supposed to hold outstanding 'combined works of nature and of humans', has maintained nearly 20 years of silence with regard to WHCLs and only became active recently. Why is this so? Is WHCL a totally new concept, type and approach for heritage conservation for China, like the international community's recognition? Is there nothing new for China? Is it China's lack of knowledge, understanding or interest in WHCLs? To what extent have WHCLs influenced China's recognition of heritage conservation? This paper aims to provide answers to these questions by reviewing the nature-related heritage conservation practices in China during the last two decades.

\section{Cross-Cultural Confusion: Application of World Heritage Concepts in China}

China has always been confused with World Heritage. First of all, World Heritage is the product of Western culture. China was a latecomer in this field, having been ratified to the Convention only in 1985, 13 years after the Convention was created. Without a thorough understanding of the cultural background, contextual origin and value orientation of many concepts of World Heritage, China was basically in the following-and-learning stage before 2010 . Secondly, due to historical and cultural differences, World Heritage in China's conservation practice brought great conflicts and contradictions to Chinese cultural tradition. Thirdly, up until 2010, there was cross-cultural confusion and misunderstanding of the concepts of World Heritage in China due to cultural differences and lack of adequate international communication. Once proper understanding and mastering of the basic rules about World Heritage were obtained, China began to move from a passive follower to an active participant and contributor.

The Convention aims to protect both natural and cultural heritage. Before the concept of WHCL was born, the protection of nature and culture in World Heritage was separated. The World Heritage and management requirement, which are based on the detachment of culture and nature from the Western philosophy, greatly impacted China's national heritage conservation system since the properties were inscribed on the World Heritage List. To understand such impacts, we need to understand the traditional Chinese perspective on the human-nature relationship.

\section{The Traditional Chinese Philosophical Founda- tions of Human-Nature Relationship}

The traditional Chinese view of nature has its philosophical origins in Confucianism and Taoism and has continued to evolve through history. The Chinese have maintained a philosophical, humanist, and holistic attitude to the human-nature relationship which is distinguished from the traditional Western human detachment from nature (Moore 1967; Chan 1967; Wang 1990; Zhou 1999). From the Chinese point of view, nature has never excluded human activities; instead, it is a place that always embraces humans. Nature is the place where the natural beauty and cultural artefacts are in 'perfect oneness' and present the Chinese ideal of nature as beautiful, peaceful, spiritually charged, and gracefully and proportionately inhabited by human beings.

Notably, nature has been an important object in Chinese culture throughout its thousands of years of history. The perceived nature was strongly underpinned and filtered by Chinese philosophy centred on human-nature relationship. Chinese philosophy was deemed practical and played an important and unique role in Chinese daily life. This philosophy was considered the guide for everyone to follow and had permeated all political, social and cultural aspects (Lin 1998, 2000).

In general, there are two main schools of philosophy, orthodox Confucianism and supplemental Daoism, both of which date back about 2,500 years in China. Confucianism took responsibility for politics and ethics because of its social involvement, with positive and morally cultivated attitudes. In Confucianism, 'the wise man delights in water, the good man delights in mountains' (zhizhe yaoshui, renzhe yaoshan $)^{1}$, which meant nature is greatly valued for humanised ethical and moral qualities, and is the place for moral cultivation. Daoism prevailed due to its negative outlook on human society and its romantic retreat in nature. Daoism attests that within nature lies the essential ontological values and great beauty. It is associated with the recluse, retirement to the mountain, the worship of rural life, the pursuit of spiritual freedom and the romantic personality, and the banishment of all worldly cares and worries. It derives the most characteristic charm of Chinese culture, the natural and rural ideal of life, art and literature (Lin 2002, 116). 
Although there were differences in value orientations, Confucianism and Daoism reached common ground. Both of them posit that 'oneness with nature' is the eternal objective of human life. Humans have been part of nature and human-nature had always been an integrated whole. Such humanistic, ethical, aesthetic and romantic beliefs underpinned the Chinese landscape practice for the twoand-a-half millennia. 'Harmony' became the golden principle of human-nature relationship. The practice of such relationship was not only aimed at combining nature and humans, but at pursuing a much higher level consistently and consciously, to poetically living with nature forever. As the result, the Chinese landscape represents the Chinese cultural perspective of nature. Conversely, the Chinese philosophy has shaped Chinese landscape ideas and activities.

Reasonably, either wilderness or pristine nature was not within the scope of Chinese appreciation in history. What the Chinese traditionally valued is the nature that has been aesthetically and morally enhanced by cultural refinement. Indeed, one might go so far as to say that historically the Chinese valued the nature that imitates art more than the other way around. Moreover, loving and traveling to morally and aesthetically idealised nature was the prime virtue of the 'good man' according to Chinese principles of moral and aesthetic cultivation (Lin 1998, 2000; Feng 2004; Yang and Zhang 2001; Yu 2001; Shen 2002; Wang 1990).

In general and distinguished from the West, the traditional Chinese view of nature is marked by the following characteristics (Han 2006, 91):

1. It is humanistic rather than religious.

2. It is aesthetic rather than scientific.

3. There is great value and beauty expressed by nature.

4. Nature is consistent with human culture.

5. Nature is the extension of home; it is an enjoyable and inspiring place.

6. Artistic representations of nature are more beautiful than their originals.

7. Nature that is managed to imitate art is more beautiful than uncultured nature.

8. Natural aesthetics is highly developed in China.

9. Traveling in nature aims to be companionable and enjoyable, instead of solitary and physically daunting.

\section{Cultural Landscape: A Problematic Concept}

Etymologically, the word 'landscape' is a creation of the English-speaking world with Germanic roots, particularly when we refer to cultural landscapes (Taylor 2007). Taylor pointed out that there is a slippage in meaning resulting from a tension apparent in the nuances of the application of the term between Western and Eastern (Asia-Pacific) cultures. Therefore, when the term 'cultural landscape' is used in Asia there is confusion on what it really means.

There are major differences in understanding in the terms 'landscape' and 'cultural' (Roe 2007). From the above perspective of Chinese traditional cultural philosophy, a human-nature-centred landscape is a priori moral, aesthetical and cultural construct. Therefore, 'cultural landscape' is dubious. It is redundant to put 'cultural' in front of 'landscape'-even as 'a useful tautology' (O'Hare $1997,47)$. This is similar to Fowler's argument (2001) that the term 'cultural landscape' is meaningless, particularly in a country like the UK where all landscapes are influenced by humans. It is confusing and culturally difficult for the Chinese to understand that term because of the lack of the concept of a culture-free, purely 'natural' landscape-that is, the concept of wilderness rooted in the western philosophy.

Augustin Berque's (1993) concept of landscape may give the closest expression of what it means from the Chinese traditional perspective: 'Landscape is not the environment. The environment is the factual aspect of a milieu: that is, of the relationship that links a society with space and with nature. Landscape is the sensible aspect of that relationship. It thus relies on a collective from of subjectivity.' (Berque 1993, 33)

Berque's landscape concept fits with the Chinese traditional context in three aspects. Firstly, landscape is not the physical surroundings; it only refers to those sensible and perceived part. Secondly, it is a nature-related concept and a social construction on nature. Thirdly, it is subjective awareness and its result on nature. The essence of landscape is the cultural and social constructive process and the result of such human-nature interaction. Therefore, landscape embodies not only the cultural identity but also the cultural limitations.

The term 'culture landscape' also encounters semantic difficulties in the Chinese language. Language is the icon of culture; there are subtle and opaque differences, especially between different languages, or more accurately, between different cultures. In Chinese, it is hard to find a single word that corresponds to the English word 'landscape', which has the Germanic root of landschaft. Instead, we have to find several words to layer the meanings of landscape, all connected with nature. Jiangshan (river and mountain) might be the synonymous with landschaft, which symbolises territory, region, tract of 
land defined by natural geographical coordinates such as rivers and mountains. The landscape idea associated with pleasant nature scenery is referred as fengjing in Chinese. In ancient Chinese, feng initially means atmosphere or air and jing means light. Both feng and jing are sensory and intangible natural features. In the $5^{\text {th }}$ century these two words were put together as a term referring to a view of pleasant natural scenery (Obi 1989). There is another important word referring to landscape: shanshui (mountain and water), which is also the renaming of nature. Shanshui became fengjing which symbolised ideal nature, dates back to the Wei Jin, Southern and Northern Dynasties (220-589 $\mathrm{AD})$. This was the milestone that marked 'nature' as an independent aesthetic objective, which is more than 1000 years earlier than in the West. Shanshui culture, shanshui painting, shanshui poem, shanshui travel, shanshui garden and even shanshui city all developed into an independent cultural branch and became the most characteristics of the Chinese culture (Han 2015a).

From the above, it is clear that 'landscape' has multiple and specific meanings. Its connotation and extension in Chinese is different from that in English. Part of the cultural dimensions of the concept of landscape applied in WHCLs, i.e., to reflect values on specific techniques of sustainable land use especially in rural landscapes, is beyond the Chinese cultural context. Although rural had been economically important for the agricultural China, rural landscapes are mostly related to pastoral scenery, aesthetically enjoyed by the social elite in history. Today, rural landscapes are still undervalued because of this cultural tradition and such preference is clearly reflected in China's heritage conservation.

\section{World Heritage Categories and Cross-Cultural Confusion in Application}

From the Chinese humanist view of nature, the separation of natural heritage and cultural heritage in the World Heritage is confusing and arbitrary. The application of the early categories of World Heritage had further brought huge negative impacts on China's heritage areas, especially on the nationally designated Scenic and Historic Interest Areas, where nature and culture are outstandingly oneness and with remarkable associative cultural significance. These areas are also most significant components of China's World Heritages. To date, 42 of China's 53 World Heritage Sites are Scenic and Historic Interest Areas or partly located in these areas. They were respectively inscribed as cultural, natural or mixed heritages, and only five fortunately entered into the cultural landscapes.
Before the inscription of World Heritage, culture and nature were harmoniously interweaved in these properties under the umbrella of national designation of Scenic and Historic Interest Areas. But now, their values are artificially separated. The early conservation requirement derived from the World Natural Heritage resulted in two unfortunate consequences: one is the removal of local inhabitants from these areas, which caused the rapid disappearance of the living traditional culture in nature; the other is the restriction of human-made structures in these areas (Guo 2003; Zhang 2003; CWHN 2004). These management policies in the name of natural heritage preservation were strongly against the traditional Chinese cultural values, resulting in cultural stagnation and retrogression in these sites. The detachment of culture and nature created moral, cultural and social crises while dealing with ecological crises in China, especially in the 1990s. If such policies had existed in ancient times, will we still have the genius creativity of the Great Wall in World Cultural Heritage today?

A typical example that illustrates the conservation bias and Chinese dilemma is the Jiuzhaigou Valley Scenic and Historic Interest Area inscribed as a World Heritage Natural property in 1992. Jiuzhaigou in Chinese means 'valley of nine villages'. It had been a traditional human settlement area in the high mountains with colourful water and a thousand-year history. Ethnic groups had lived there farming and grazing for generations. However, since its nomination and inscription, the orientation of conservation became purely natural and pristine guided. Farming and grazing were prohibited. Local people were reduced to becoming a tourist spectacle, the tourists' image of the ethnic herdsmen, although with high economic compensation. The evolving landscape with its vivid cultural history has been erased by eco-restoration. It has become an untouched so-called pristine area of artificial 'earthly fairyland' or 'fairy tale world', i.e., a fake landscape.

However, the model of such eco-restoration and the partnership between the management authorities and the local communities was commended by the World Heritage Committee and conveyed the wrong message to the Chinese government (UNESCO 1998). Soon, the 'pristine ecological conservation model' became prevalent in China's heritage conservation in nature-dominated areas. I called this model 'China's new wilderness' (Han 2005). In terms of its core spirit, the pristine nature voids of humanity in consistent with western wilderness ideas but strongly against the Chinese tradition of nature. The wilderness idea of North America came into China imperceptibly 
with World Heritage and such impact continues in China's natural heritage conservation, even in today's so-called 'cultural landscapes'.

Cultural and social conflicts were intensifying. The saddest thing about this process is that 'we are happily destroying our culture' (Feng 2001; Han 2005) in the name of 'natural conservation' without cultural awareness. The landscape was being misinterpreted beyond the respect and understanding of the land context inhabited by people. We began to turn a blind eye to the gods in the beautiful mountains and waters that the ethnic people believe in. What China went through in the 1990s was a crisis of detachment of culture and nature in World Heritage practice, similar to Australia in the 1970s when National Parks authorities sought to create 'pristine' wilderness areas by erasing the traces of Aboriginal habitation (O'Hare 1997, 29). The impact of World Heritage can also be seen as an impact of globalisation. The ensuing separation of culture and nature saw the beginning of a struggle between Chinese traditions and international perspectives of nature.

It seems logical to say that China, as a country of 'oneness with nature' and suffered by the detachment of culture and nature in World Heritage practice, should have embraced World Heritage cultural landscape with open arms. Unfortunately, because of the lack of international information exchange, China was not aware of the birth of the WHCLs in 1992 and this historical cultural turn of the World Heritage. It was not until 2007 that China had its first academic discussion regarding WHCLs.

Furthermore, there was a major misunderstanding of mixed heritage in China's World Heritage practice. China had been interpreting World Heritage categories according to our own cultural traditions, and there was a significant difference from the recognition of the international community. From the holistic Chinese cultural perspective, mixed heritage is naturally considered as the outstanding interactive work of nature and of humankind, which is indeed expressed in today's WHCLs. It was the reason why China was particularly keen on mixed heritage in the past. Among today's world 38 Mixed World Heritage properties, China accounts for four, which is above $10 \%$ of the properties. In the previous nomination dossiers for mixed heritage, China had been interpreting the profound culture-nature relationship, and that was why the nominated Lushan National Park and Mount Wutai to the mixed Heritage were finally inscribed as cultural landscapes.

Herb Stovel and Peter Fowler (2003b, 18) had clear explanations of the difference between mixed heritage and cultural landscape.
Cultural landscapes are those landscapes which reflect the interaction of human beings and nature - and mixed landscapes are those landscapes that have important cultural values AND important natural values, but NOT values exemplifying the interaction between culture and nature. For World Heritage, cultural landscapes are treated as cultural sites not natural sites ${ }^{2}$.

It seems it is clear in World Heritage that cultural landscape focuses on an inseparable organic whole formed by the interaction of two events of nature and culture, while the nature and culture in the mixed heritage are separated. However, that has been never clear for the Chinese and I believe for many other nations, too, because the culture in the nature that has no reason to be related is unthinkable. Although Stovel (2008) explained that the language confusion does not matter, and that what is needed is more training and education. Still, I question why we should be trained to understand to accept mixed heritage separately? I consider language as very important because it is a product of culture. As an international instrument, the use of language and concept in World Heritage should also be culture-inclusively universal.

\section{China's Silence on the World Heritage Cultural Landscapes}

All these reasons have caused China's silence with regard to WHCLs. In 1996, Lushan National Park was inscribed as the first Chinese WHCL. 13 years later, in 2009, Mount Wutai became the second in China, followed by the West Lake in 2011, the Hani Rice Terraces in 2013 and the Huashan Rock Art Scenic Area in 2016. It can be seen that only almost 20 years after the birth of the WHCLs, China began to truly move in this field. Before 2011, China has never voluntarily nominated a WHCL. Neither Lushan nor Mount Wutai were nominated to become WHCLs by China but inscribed as cultural landscapes.

China's silence in WHCL caused great concerns and considerable suspicion and misunderstanding in the international stage. It was observed that 'China can now be seen as a major holder of cultural landscapes among its existing World Heritage sites' (Fowler 2003b, 60), yet 'none were nominated as such, presumably deliberately, most came forward as "mixed sites"; [and] it would be interesting to discover whether this is related to administrative questions' (42), and 'it would be helpful if [China as major holder of cultural landscapes] could be formally recognised in some way' (60). This observation confirms China's misuse of the concept and category of mixed heritage as cultural landscapes. Fowler (2003b) suggested that 
almost all the Chinese-inscribed properties in that period, such as Mount Emei, Mount Wudang, Mount Qingcheng, which are all Scenic and Historic Interest Areas in China, could be re-nominated as cultural landscapes. Again, this proves that Scenic and Historic Interest Areas are the representative landscapes of the 'combined work of nature and of humans'.

Unfortunately, China was completely oblivious to what was happening in WHCLs and the international questioning at that time, thus, it did not respond. The real reason is not because the administration deliberately avoided it, as Fowler presumed. Indeed, it is really quite simple: China knew nothing about the birth of the WHCL concept until the extensive and in-depth discussion in the journal of Chinese Landscape Architecture in 2007. China's journey from knowing the World Heritage to acceptance and then contributing in international frontier was a long one.

Lushan was the root of the Chinese confusion on WHCLs. It was inscribed on the World Heritage List in 1994. However, it was initially nominated as mixed heritage. Its cultural landscape values and the category was later suggested by the International Council on Monuments and Sites (ICOMOS) during the evaluation process. The natural values and the striking natural scenic beauty that has inspired Chinese artists, writers, philosophers, and scientists recognised by ICOMOS were denied by the International Union for Conservation of Nature (IUCN) (ICOMOS 1996; IUCN 1996). Finally, 'the Committee decided to inscribe this property on the basis of cultural criteria (ii), (iii), (iv) and (vi) as a cultural landscape of outstanding aesthetic value and its powerful associations with Chinese spiritual and cultural life' (UNESCO 1996). The process of listing was intricately confusing. Today, it is still a challenge for IUCN how to evaluate natural beauty and natural aesthetics (IUCN 2013).

During the evaluation process, the State Party of China was not required to re-submit the nomination dossier and to justify the new changed cultural landscape values from a mixed heritage. In fact, the evaluation process itself was problematic. Although there was a joint ICOMOSIUCN expert on site mission, the evaluation for values was obviously separate. As noted in the ICOMOS report, 'the evaluation is concerned solely with the nomination under the criteria for cultural properties, the evaluation of the natural qualities being covered in the IUCN evaluation'. Such separation greatly affected IUCN's understanding and evaluation of Lushan's natural aesthetic values. Until 2010, Lushan's OUV as a WHCL was not understood by the Chinese so much so that cultural landscapes inscription was a lower level than the cultural, natural and mixed heritage in World Heritage (Han 2011a, 2011b). And, the ICOMOS-IUCN hand-in-hand evaluation did not happen until the ICOMOS-IUCN started the 'CultureNature Journey' from the 'Connecting Nature and Culture Project' in 2013 (IUCN and ICOMOS 2013).

What made it more confusing was that after inscription, Lushan was not either officially listed in WHCLs List on the World Heritage Centre (WHC) official website, or appeared in Fowler's table of Official World Heritage Cultural Landscapes (Fowler 2003a, 43). It had been in the Cultural Heritage List until 2015 and then moved into the Cultural Landscape List by the WHC. Today, it is still not sure if Lushan was the first inscribed WHCL of China. No one has explained such a confusing situation to China. The inadequate process of nomination, communication, evaluation and inscription resulted in China losing a precious historical opportunity to dialogue in the 1990s, at the time of the rise of the cultural landscape in World Heritage.

The perplexity of Lushan was exacerbated in 2008 when China nominated the famous Buddhist Mount Wutai to mixed heritage. The entire process repeated the Lushan confusion. Mount Wutai was suggested to cultural landscape category during evaluation and was inscribed as a WHCL again. At that time, it was noted that cultural landscape is different from mixed heritage, and cultural landscape was within the cultural heritage category. The inscription of Mount Wutai prompted the State Party and academics to clarify their understanding of WHCLs and mixed heritage.

The difference between the cultural landscape and the mixed heritage remained unclear, even though West Lake was moved to cultural landscape from a natural and cultural mixed heritage on the China's World Heritage Tentative List in 2006. China's silence continued until the nomination of the West Lake to the WHCL in 2010.

\section{The Rise of World Heritage Cultural Landscapes in China}

\section{World Heritage Cultural Landscape Debates in China}

In 2007, a group of international papers on cultural landscapes was organised by the author as the first special issue for the national official academic journal of Chinese Landscape Architecture. However, it encountered great difficulties in publication because the concept of cultural landscape was deemed too confusing. Fortunately, the 
papers (Zangheri 2007; Roe 2007; Taylor 2007; Han 2007) were finally published and the invited international experts and ICOMOS-IFLA International Scientific Committee on Cultural Landscapes (ISCCL) colleagues made significant contributions to the introduction of the concept and practice of WHCLs to the Chinese readers. In October 2008, China had the first International Symposium in Guizhou on Village Cultural Landscapes, while Hangzhou held a Forum on Cultural Landscapes. These milestone events signalled the awakening of cultural landscape thinking in China.

With the deepening of the debates, exchanges and understanding, it was gradually known that the essence of WHCLs, i.e., 'the combined work of nature and of humans' can be shared as a common ground with the Chinese 'oneness with nature'. Moreover, WHCL could be the right platform for China to make great contributions. The three categories of WHCLs may give China an opportunity and new perspectives to re-examine Chinese culture and its landscape practice.

\section{UNESCO World Heritage Conservation and Man- agement Program in China: Lushan Cultural Landscape Value Research}

In 2010, in view of the WHCL confusion occurred in Lushan and Mount Wutai, as well as the great contribution of the Scenic and Historic Interest Areas to World Heritage, the UNESCO Beijing Office launched and commissioned Tongji University to undertake the Project of Lushan Culture Landscape Value Research ${ }^{3}$ under the World Heritage Conservation and Management Program in China. This project kicked off a systematic study of the cultural landscape research in China's Scenic and Historic Interest Areas. Through a number of activities, such as onsite open lectures to communities, workshops, questionnaire survey and interviews of stakeholders, historical research, etc., the concept of WHCL was interpreted and Lushan's cultural landscape values and attributes which were unclear in the nomination and inscription process were identified and interpreted. The project also conducted the findings of the unique Chinese values of culture-nature interaction in the Scenic and Historic Interest Areas (Han 2011a, 2011b), which could be greatly contribute to WHCLs. The UNESCO Lushan Landscape Research Project has become a benchmark for Chinese studies on the cultural landscape of the Scenic and Historic Interest Areas. Through this project, it was realised that these areas are indeed the most representative practice of the Chinese view of nature.
The Lushan Project had actively dispelled the crosscultural confusion of WHCLs existing in China for a long time, kicked off the systematic research of Chinese heritage landscapes with the aid of the perspectives of the WHCLs as well as the Chinese. It constructed a bridge between China and World Heritage and played an important role in recognising WHCLs in China. Moreover, by that time, the international difference between WHCLs and mixed heritage had been clarified.

Around the same time, intensive studies on the cultural landscape values of the West Lake, the Slender West Lake and Huashan Rock Art Scenic and Historic Interest Areas were launched. Preparations began for the WHCL nomination of West Lake in Hangzhou. In 2011, the State Administration of Cultural Heritage (SACH) actively followed the international frontiers and trends of World Heritage (Shan 2009) and set out to update the State World Heritage Tentative List, which was updated in November 2012. There were major amendments in the Tentative List, presenting two remarkable features in the strategy in the World Heritage nomination. Firstly, the categories were expanded. In addition to the conventional and traditional ancient buildings and archaeological sites, a number of new categories of historical villages and towns, cultural landscapes, cultural routes and industrial heritages had been added; agricultural heritage cultural landscapes as a new type of cultural landscape appeared for the first time. Secondly, there was a significant increase in the involvement of ethnic culture conservation in the cultural diversity and cultural vulnerability. Among the 59 sites in the latest State Tentative List submitted to UNESCO WHC in 2017, there are 10 that may contribute to the WHCLs (UNESCO 2018b).

In 2008, an international symposium on Village Cultural Landscape was held in Guiyang, China ${ }^{4}$. The 'Guiyang Proposal' became China's first document related to the conservation of rural cultural landscapes that extends the conventional rural architectural conservation to rural living space, production space and ecological surrounding, including the spectrum of cultural, social and ecological process. The cultural landscapes now include the traditional eco-wisdom on surviving and sustainable land use and social organisation system. From then on, a series of continuous documentation work on rural intangible traditional culture, such as paper making, printing and dyeing was carried out in the Miao and Dong ethnic groups in the southeast mountainous area of Guizhou Province, represented by Dimen Ecological Museum. The southeast of Guizhou became the focal point of rural, small settlement cultural landscape conservation in China. 


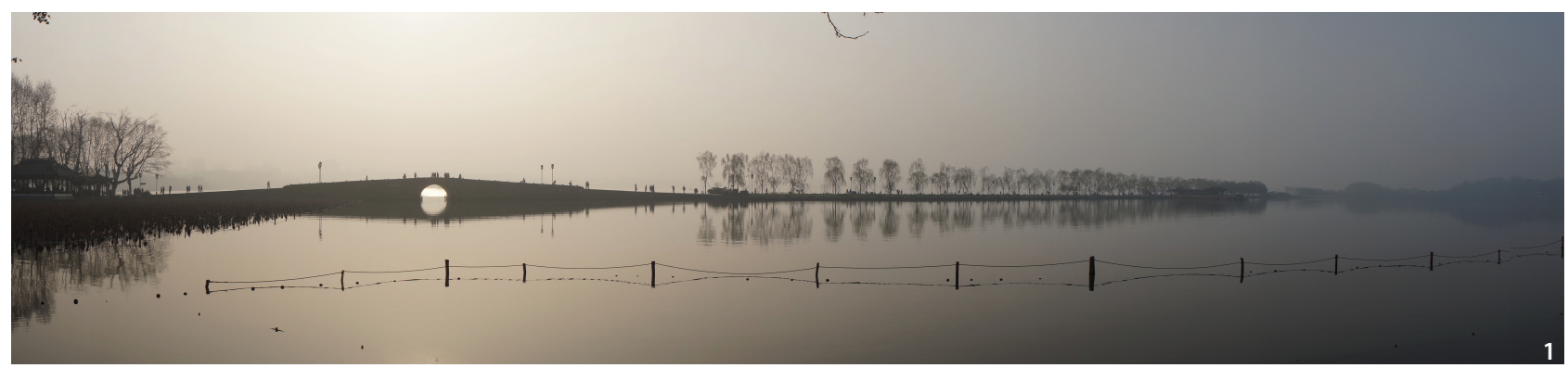

Figure 1 The West Lake in Hangzhou: The Heaven on Earth (Source: the author).

\section{The WHCL Nomination of the West Lake in Hangzhou}

In 2011, after more than a decade of the preparing for the nomination in the State Tentative List, the West Lake was successfully inscribed in the World Heritage List, the first WHCL nominated and inscribed upon China's own initiative. The inscription of the West Lake WHCL is of a landmark for the country; it is 'a significant historical contribution to the Asian region and the World Heritage, which represents the conscious rise of the Eastern culture ${ }^{5}$. For the first time, the Chinese in-depth values are embodied in a WHCL, which had not been elaborated in Lushan and Mount Wutai previously.

The West Lake, cultivated by the Chinese culture for more than 2,000 years, is known as a masterpiece of 'the Heaven on Earth'. As a national cultural icon through history, the lake and its surroundings carry the Chinese subtle, romantic, and elegant ideas of nature. It is one of the most distinguished living cultural landscapes in China which perfectly represents the Chinese philosophies of 'oneness with nature' and the art of living. It has achieved the most romantic and aesthetic objective of the Chinese: to create a worldly heaven for their life, for harmony, enjoyment, and poetically living with nature forever (Figure 1).

The nomination history of the West Lake is thoughtprovoking. The West Lake had been on the Tentative List of mixed heritage for years. Before it was considered for the cultural landscape category, there was no way to interpret such a wonder of Chinese culture. Through an international experts' eyes, there are thousands of lakes like this in their hometowns. The water is not deep enough and the surrounding mountains are not high enough; thus, it could be neither a nature heritage nor a cultural heritage, which meant it is impossible to be considered for mixed heritage. However, the cultural value of the West Lake, as it turns out in its inscription to WHCL, has nothing to do with how high the mountains are and how deep the water is. Its value of the West Lake lies in its 2000-year thick mud at the bottom of the lake. Therefore, the most important thing is to be on a right platform to be able to share the story with other cultures.

\section{HUL Pilot Project in Yangzhou: The Cultural Land- scape Values of the Slender West Lake to the City}

The Lushan research project and the West Lake inscription greatly promoted the research on the diversity of cultural landscapes in China. The nomination and inscription of cultural landscape of the Honghe Hani Rice Terraces in 2013 and the Zuojiang Huashan Rock Art Cultural Landscape in 2016 show that China has gradually stepped onto the WHCL platform. The Chinese State Party and experts began to actively participate in the drafting of important international documents, such as the Recommendation on the Historic Urban Landscape (HUL) and IUCNICOMOS Connecting Nature and Culture Project to contribute Chinese values. Chinese experts also played an important role in the regional activities of the ICOMOSIFLA ISCCL.

On November 10, 2011, UNESCO's General Assembly adopted a new international instrument: the HUL Recommendation defining it as the urban area that is the result of a historic layering of cultural and natural values and attributes ${ }^{6}$. HUL is as an innovative way to understand and interpret living cities in a similar fashion as cultural landscapes. Based on the recognition and identification of a layering and interconnection of natural and cultural, tangible and intangible, international and local values present in any city, HUL is an integrated and comprehensive approach to identify and understand the urban values, which are at the heart of the identity and character of the city (Van Oers 2010, 2012). It also provides a useful tool to connect the old and the new in the city through detecting and integrating the historic context in the dynamic social and economic changes.

HUL is of great significance for conservation and sustainable development in China's rapid urbanisation 


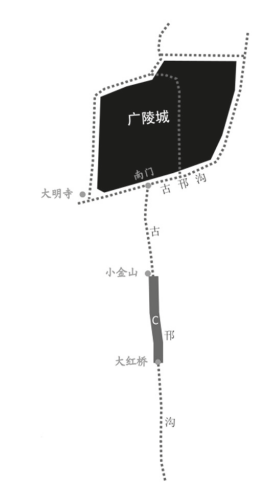

486 BC - 458 AD Spring and Autumn Period to Southern and Northern Dynasty

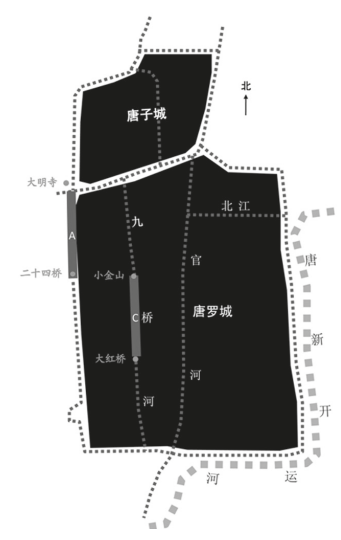

$9^{\text {th }}$ Century AD Tang Dynasty

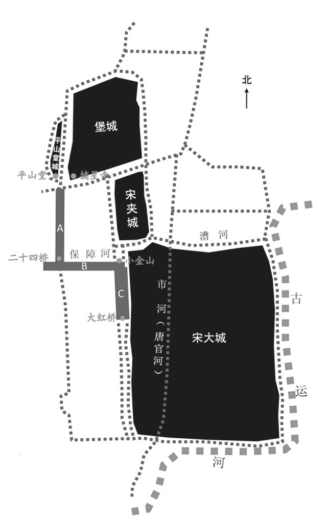

$13^{\text {th }}$ Century AD Southern Song Dynasty

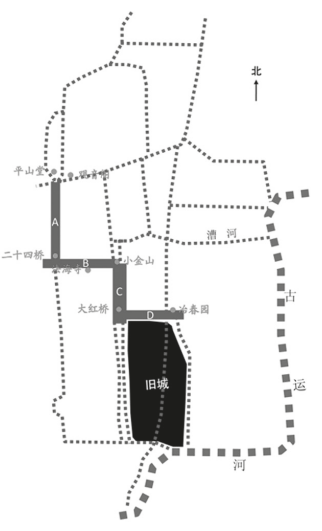

$14^{\text {th }}$ Century AD

The end of Yuan Dynasty The beginning of Ming Dynasty

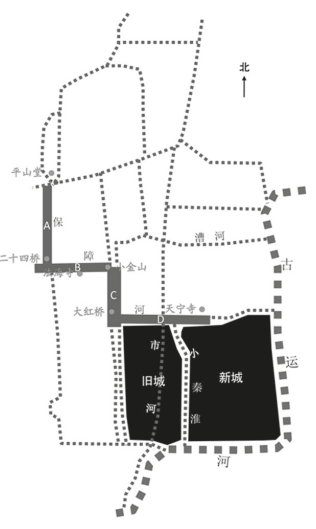

$15^{\text {th }}$ Century AD and after Ming Dynasty and Qing Dynasty

The Slender West Lake

The Walled City

The Water Network

Figure 2 The re-mapping of the history of the Slender West Lake intertwined with the city of Yangzhou (Source: the author).

context. The Chinese State Party and the expert participated in the entire process of drafting the document and brought it back to China for implementation. A special program of research and technical assistance on the implementation of the HUL approach in China was developed at Tongji University and World Heritage Institute of Training and Research for the Asia and the Pacific Region under the auspices of UNESCO Shanghai Branch (WHITRAP-Shanghai) in 2012. It was part of a strategic framework that aims to increase understanding of and undertake work in sustaining and enhancing the quality of the urban environment in the country. Soon after, WHITRAP-Shanghai became the focal point of implementation of HUL worldwide. The China roadmap for HUL implementation of Historic Urban Landscape was announced and a cooperation agreement signed between Hangzhou Municipality and UNESCO in July 2011.

Earlier in 2010 while the HUL was still being drafted, the ancient city of Yangzhou, backed by a 2,500-year history, became the Pilot Research Project ${ }^{7}$ in China. A systematic theoretical framework was designed to examine the iconic cultural landscape of the Slender West Lake in the city and to explore the layering of the meanings of the landscape within the urban social, political, economic, cultural and natural context. The project was not only aimed to study the Slender West Lake, but also to implement the HUL and contribute to the clarity of the identity of the city by shaping the direction and structure of urban development.

As a pilot HUL project, the Slender West Lake's history, values, meanings, symbolism and its status of authenticity and integrity have been re-examined and re-interpreted by applying the HUL inclusive approach. It was the first time a research broke the boundary of a scenic area and extended the history research of a landscape to the broad urban context to explore the interweaving destiny between the lake and the city (Han 2015b). It was a rebirth both for the lake and for the city. Particularly delightful was the finding that the lake essentially was a city moat; it was the origin of the ancient city and witnessed the evolution of the city (Figure 2). This saved the lake from isolated aesthetic landscape conservation separate from the urban context and strengthened the city. During this process, the power of the landscape was not limited to within the conserved boundary, but was spread to the whole city, and all its people. This project showed that landscape research is a powerful vehicle that bridges the old and the new; and includes historical wisdom in today's cultural confidence. It is also a powerful engine to help the politicians define the conservation objectives, development strategy, and reform of urban cultural structure with strong local identity.

\section{Relearning Rural Landscape Values and Digital Documentation}

China has also been inspired by the rural landscape conservation in WHCLs. The country is an ancient agricultural civilisation with excellent land use skills and land culture. The cosmic view and emotion towards nature was initially based on the awe that was felt towards the land and nature. However, the peasants, the wisdom of surviving and living on the land and the sustainable use of the land, had been severely undervalued in Chinese traditional culture as well as in today's heritage conservation. 

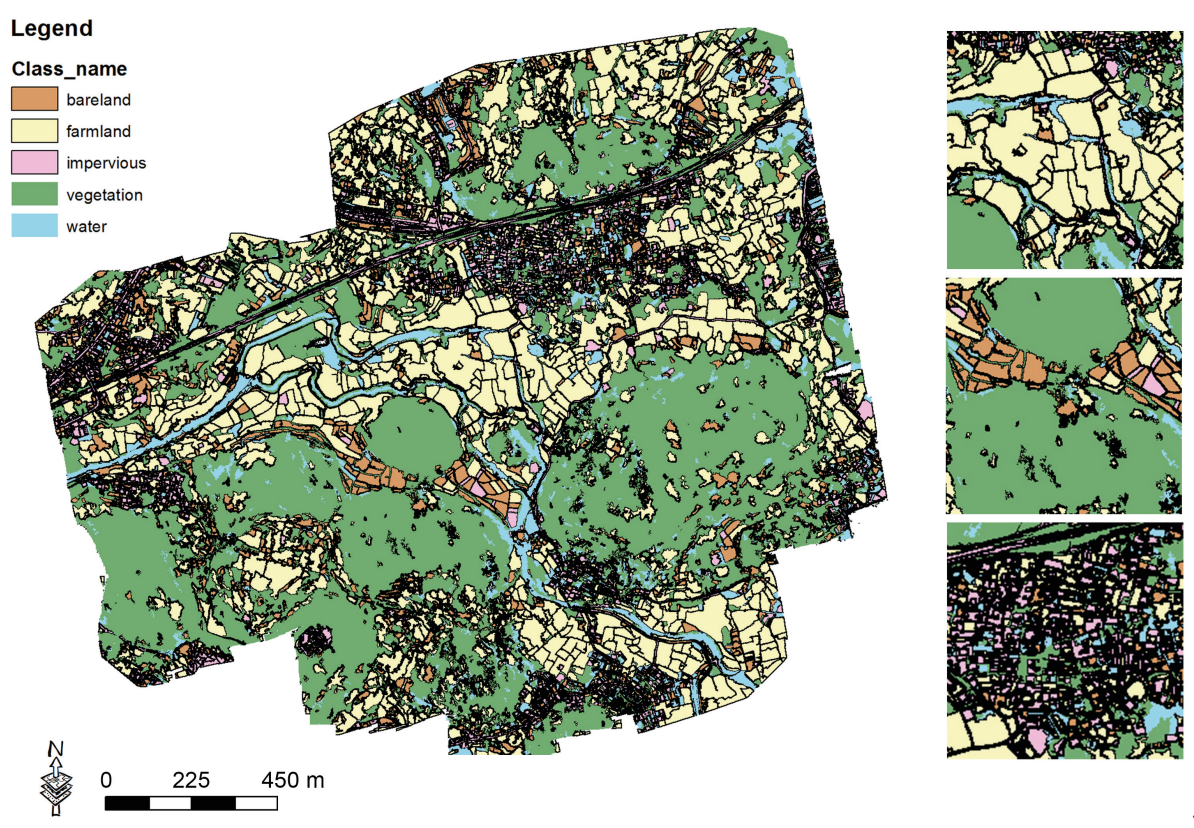

Figure 3 Landscape elements classification based on multispectral image, Baojuatun Village, Guizhou Province (Source: Yujie Cao and 3 Yuan Zhou).

In ancient China, rural life was accorded with Daoism's ideal way of 'natural life. The hard peasant life was neither appreciated nor culturally valued because peasants, fishermen and farmers 'lived in nature but could not consciously acknowledge the happiness of the hermit, their hearts and bodies were limited by practical considerations that prevented them from enjoying the beauty of nature and understanding its meaning with a free heart' (Zhang 2008, Chapter 137). Scholars, although reclusive in nature, seemed to enjoy a rural ideal, but in fact they 'can only water gardens but are unable to cultivate the land, can only remove grass but are unable to cut firewood' (Zhang 2008, Chapter 26). Therefore, rural life and its landscape were only valued as an aesthetic objective and philosophical ideal. Rural landscape was an elite cultural image.

In contrast, the rural landscape conservation has been of international importance. Scazzosi (2018) has clearly reviewed the development of conservation history of rural landscape as heritage in the World Heritage. Today, the urban-rural conflict has become one of the critical issues in developing China. Problems of urbanisation, the rapid disappearance of rural villages and landscapes, declining rural population and traditional knowledge of sustainable land use, the transformation of social space driven by capital, and etc. has forced China to look into the conservation of agricultural rural landscapes, and to re-evaluate their heritage values. The Food and Agriculture Organisation (FAO), along with the Globally Important Agricultural Heritage Systems (GIAHS), the ICOMOS-IUCN Connecting Culture and Nature Journey, and the ICOMOS
Principles on Rural Landscapes as Heritage, have garnered attention in China. Regarding agricultural heritage conservation, China has done better in the GIAHS than in the WHCLs, with 15 GIAHS sites to date.

Rural landscape documentation and archival is the most urgent issue for China. Technology and expertise are concentrated in cities, and the conservation is still mainly focused on architectural buildings and historic city centres. Rural heritage conservation is short on capital, technology and expertise, especially strategies and approach. With urbanisation in the recent years, the rural population has been rapidly moving toward urban areas. The speed at which the villages are disappearing is striking. More than 900,000 villages disappeared over the decade between 2000-2010 (Chinanews 2015). Many villages not known by the outside world have already disappeared, as if they never existed. This is a major loss for history, culture and eco-wisdom of the bio-cultural diversity. Therefore, for rural areas, especially in those remote areas and in deep mountains, the need for efficient and systematic rural cultural landscape documentation is extremely urgent. This is an obvious research and management gap not just in China but also in the world.

In order to establish efficient digital workflows and standard specifications for rural heritage cultural landscape documentation, a multidisciplinary Digital Heritage Cultural Landscape Innovation Working Group was established in 2016 at the Tongji University. It aims to address conceptual, technical and legal definitions relevant to digital cultural landscapes; to build a common understanding 


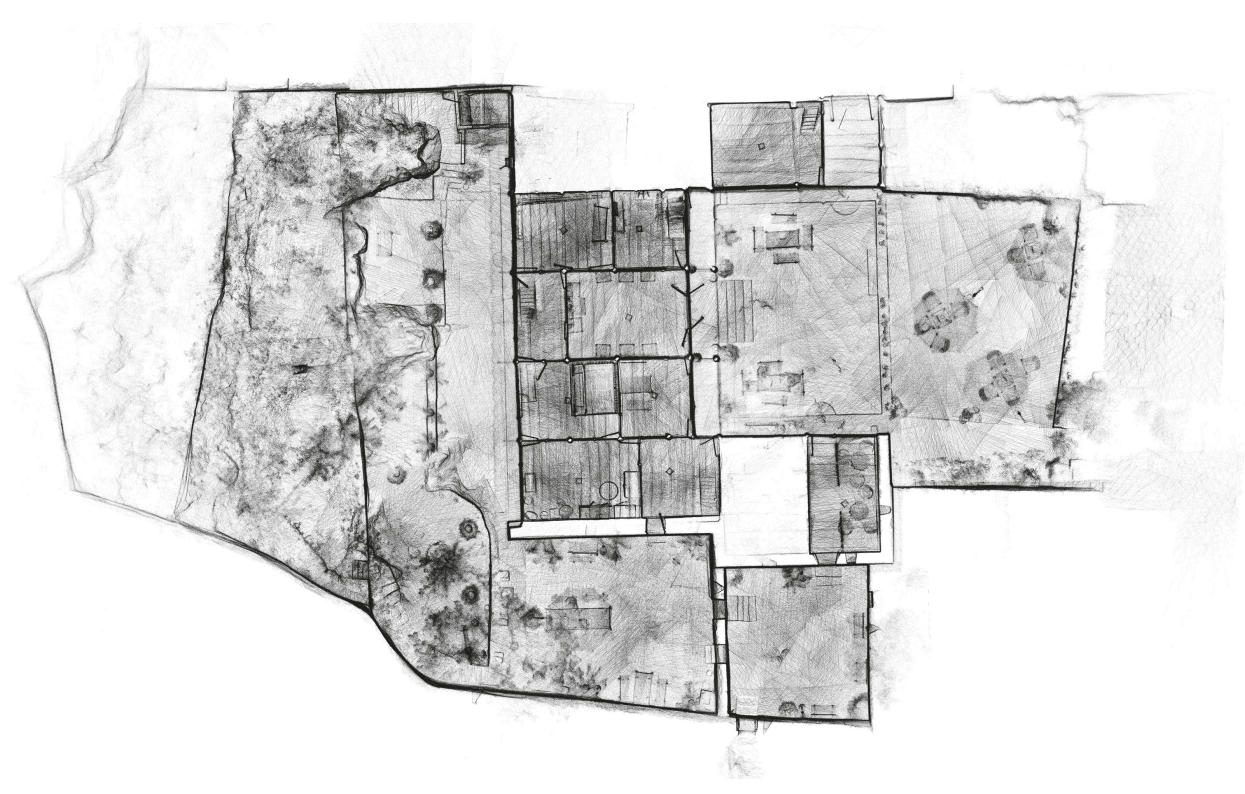

Figure 4 Point cloud map of a Tunpu house in Benzhai Village, Guizhou Province (Source: Leigh

4 Shutter and Chen Yang).

and language in order to have a fundamental basis and reach common standards; to identify emerging technical issues, innovations and tools for digital cultural landscape research and practices focusing on emerging and future documentation needs such as those in data modelling, semantics and data acquisition; and to establish standard specifications for digital cultural landscape documentation. An experiment was soon conducted in Baojiatun, a rural village with 600 years of history in the Guizhou Province. High technologies, aerial photogrammetry, laser scanning, territory photogrammetry, AR and VR filming were used in physical and intangible customary data collection based on a theoretical research design of rural landscape conservation. Within one week of onsite work, a 3D virtual model of the village, point cloud map, extraction of vector maps from the point cloud model, and digital film were generated (Figure 3, Figure 4).

Although this experimental research was done in the Chinese context, this new approach and technology could be universally applied in any international landscape conservation. Once the structural design of the standard database of cultural landscape in different sub-categories is completed, the collected data can be widely used for heritage landscape management, monitoring of changes, digital media, history and cross-cultural comparative research, etc., which will bring a revolutionary change to the management, research and communication of heritage cultural landscape conservation. Based on this experimental research and initiative, we convened a new Digital
Cultural Landscape Working Group in ISCCL in 2018 in New Delhi, which drew a warm response from the Committee colleagues.

\section{The Old and the New: The Mutual Contribution between China and WHCLs}

The above review and rethinking of the Chinese traditional view of nature, the long-term confusion about the concept of World Heritage and the rise of Cultural Landscapes, and the recent efforts on heritage landscape conservation have laid a foundation for the mutual contribution between China and the international World Heritage. Although there have been much cross-cultural confusion and misunderstanding previously, it is heartening to see that we are essentially telling the same story: a story of human-nature relationship and how nature is valued from different cultural perspectives. If this is understood and becomes our common ground, the term of 'cultural landscape' itself becomes less important. WHCLs provides a platform to share heritage landscape values and widen our horizons based on cultural diversity; it also offers a great opportunity for China to contribute and to benefit.

\section{The Potential Contribution of China's Cultural Landscapes to WHLCs}

According to Berque (1993), four criteria characterise a 'landscape civilisation': a word referring to landscape; descriptions of landscape in literature and poetry; 
representations of landscape in painting; and the art of gardening. These four criteria were first met by Taoist China around the $3^{\text {rd }}-4^{\text {th }}$ century AD.

Ken Taylor (2007) also believes that some of the world's greatest cultural landscapes of OUV exist in Asia. They represent a way of living, a continuous living history, thereby representative treasures of the world's living cultures. They are a vivid embodiment of landscape as a cultural process, as opposed to being simply an objective cultural product. The Chinese examples are thought a representative reflection of the rest of Asia. Here, landscape is not what we see; rather it is:

... a way of seeing that has its own history, but a history that can be understood only as part of a wider history of economy and society; that has its own assumptions and consequences, but assumptions and consequences whose origins and implications extend well beyond the use and perception of land; that has its own techniques of expression, but techniques shared with other areas of cultural practice (Taylor 2007).

The Chinese way of seeing nature has a significant contribution to WHCLs, which lies in three aspects: the humanist view of nature based on philosophy, the natural aesthetic theory and the typological contribution of the cultural landscapes regarding the practice.

\section{Contribution to the Philosophical Value of Cul- tural Landscape: The Chinese View of Nature}

In my view, the objective of WHCLs is to provide a historical, multi-cultural wisdom to maintain the harmonious culture-nature relationship for sustainable development. The human attitude towards nature, represented in the view of nature, is underpinned by cosmic view and environmental philosophical views. To deal with the culturenature relationship and the practice, it is essential to deal with the root, that is, the position of environmental philosophy and the view of nature.

The Chinese humanist view of nature, underpinned by philosophies of orthodox Confucianism and complemented by Taoism, is the origin of the Chinese landscape values. From cross-cultural view, China's thorough humanist spirit to embrace nature, the holistic cosmic view of being harmony and oneness with nature, is the essential contribution to the world. The Chinese integrative, active, intuitive, harmonious epistemology in dealing with culture-nature relationship is the legacy of the Eastern wisdom and universal humanity. This is China's greatest contribution to the philosophical foundation and the ultimate goal of WHCLs.

\section{The Theoretical Contribution to Cultural Land- scape: Layers of Meanings of the Chinese (Land- scape Objectivity, Subjectivity and Authenticity)}

Authenticity is always a central theme of heritage conservation. However, 'Different cultures have different ideas of what is and is not "authentic", especially in landscape.' (Fowler 2003b, 16) Composed of objective and subjective features, different levels of landscape meanings in cultural contexts point to different understandings of authenticity. To decode multiple layers of meanings of landscape requires one to be familiar with the languages that were used by the creators to encode meanings.

Underpinned by the Chinese philosophy of conscious 'oneness with nature', nature has permeated the Chinese ideology and landscape has transcended its material meanings, constructed its own symbolic meanings regarding cultural, moral, aesthetical and political signifiers, which were expressed in everyday life. The subjective and objective landscape values and their authenticity are sophisticatedly layered. Such layered authenticity is represented in symbolic and metaphorical landscapes, which are the consistently used rhetoric for Chinese landscapes based on traditional Chinese landscape theory (Zhang 1986; Wang 1990).

Zhang Chao (1650-?) of the Qing Dynasty stated incisively that there were different layers of authentic landscapes. He asserted that 'there is shanshui on the earth, there is shanshui in paintings, there is shanshui in dreams and there is shanshui in the heart' (Zhang 2008, Chapter 84). Here, he concluded with the four corresponding stages of Chinese ancient landscape history and four levels of the meanings of landscapes. In the first stage, nature was separate from human subjectivity as an objective outside world. In the second stage, nature came into human subjective consciousness selectively and was represented by humans. In the third stage, nature and humans, objective and subjective, deeply interacted with each other, but landscape was not yet able to be entirely controlled. Only at the fourth stage was subjectivity of landscape was developed and landscape could be envisaged through the subjective thought. In this stage, the free use of all-natural materials and creative abilities for the deconstruction of nature were shown in Chinese landscape gardens and landscape paintings. Along with these four stages of landscape development, the meanings of landscape moved from objective material to nonmaterial, symbolic, fluid and subjective. All landscapes conceived, created and constructed in the four stages, either tangible or intangible, are authentic representations of the interactions between nature and the Chinese. 
The understanding of Chinese landscape theory will help to decode the layers of meanings of the Chinese landscapes, to enrich the meanings of the associative landscapes of WHCLs, and to provide an eastern interpretation of authenticity to deepen and widen the scope of international cultural landscape theory.

\section{China's Contribution to the Categories of WHCLs}

As an ancient civilisation, China is rich in three categories of WHCLs. In the latest 'Research on Cultural Landscape Values and the Categorisation of Scenic and Historic Interest Areas' ${ }^{8}$ and $\mathrm{PhD}$ research, 26 sub-categories have been identified (Li 2017). In the WHCL sub-category of the designed and created landscape, the Chinese classic gardens are the most representative. In the subcategory of organically evolved landscapes, as an ancient country with great agricultural civilisation, China has great potential to contribute the wisdom and techniques of sustainable land, such as tea landscape, salt landscape, irrigation landscape. In the sub-category of the associative landscape, the Chinese humanistic philosophy can contribute outstanding philosophy-, art-, religion- and culture-related landscapes to enhance the depth and breadth of WHCLs.

Typically, China's unique contribution lies in one special type of cultural landscapes, which perfectly integrates the three sub-categories of WHCLs. They are represented by the cultural landscapes from Chinese Scenic and Historic Interest Areas. The inscribed properties from these areas, such as the West Lake, Lushan, Mount Wutai and Wudang Ancient Building Complex are best examples. They are all masterpieces of designed and created landscape, successfully evolved, sustainable land use model and the best practices of the Chinese philosophies of 'oneness with nature'.

\section{The Inspirations of Cultural Landscapes and WHCLs for China}

From Lushan and Mount Wutai, to the West Lake, the Hani Rice Terraces, Huashan Rock Art, the Slender West Lake and Baojiatun Village, there is no doubt that China has achieved great progress with regard to cultural landscape conservation, but there is still too much to learn and to do. Perspectives of WHCLs and the contemporary western cultural landscape theory are particularly important when re-examining the values and the limitations of Chinese traditional culture and landscapes and re-evaluating the current challenges of development and heritage conservation strategy.
Cultural landscape is now perceived as a major component of environmental policies associated with ethics, justice, spirit of the place, well-being, health and life quality in the international stage. It can be used to understand and reveal the characteristics of urban landscape changes powered by a capitalistic economy and impacted by globalisation as well as the social spatial relations and values embodied in them. These are currently not supported by the Chinese traditional experience. The new landscape approach provided by HUL for urban historical heritage conservation and sustainable development can help China cope with the following challenges: how to safeguard the inheritance of the cultural tradition, spirit of place and social justice, and how to maintain harmonious culturenature relationship for sustainable development during rapid urbanisation and globalisation.

HUL underpins the fundamental concept of urban areas as a series of layers through time that link past, present and future as in the construct of cultural landscape. An urban landscape consists of a pre-existing environment (involving topography, and physical and natural features), which has been modified in part or completely through the process of urbanisation by a stratigraphy of patterns, plots (built and unbuilt), infrastructure and building stock geared towards the provision of urban space for housing, work, transport, and leisure activities (Van Oers 2012). Urban landscape is a cumulative record of the succession of economic booms, slumps and innovation adoptions within a particular place, which thereby acquires its own genius loci or spirit of place (Tuan 1974; Relph 1974, 1987; Norberg-Schulz 1980).

Today's China's urban-rural conservation, monuments, separate historic towns and villages are still handled by historic conservation zoning. It is recognised that the current conservation notion of groups of buildings, historic ensembles or inner cities, identifying them as separate entities within a larger whole is not sufficient to protect their characteristics and qualities against fragmentation and degeneration. But an integrative landscape approach as a stratification of previous and current urban dynamics with interplay between the natural and built environment (Van Oers 2012), where every layered and inter-related element is necessary and integrity becomes a key consideration when dealing with the management of historical context and change in complex urban environments (Taylor 2015), has not grown of importance in China, even in the academia yet. Landscape is given far less attention than historic centre and architecture conservation and the focus of urban landscape is on 'the green landscapes' to 
beautify the city. Natural resources and process are especially ignored in urban conservation. The integrative HUL approach is difficult to implement in China because of the detachment of management system. The recognition of the HUL landscape approach is urgent for the Chinese academia and urban conservationists to connect the culture and nature, to 'marrying the old with the new' (Smith 2010) in order to restore a contextual interweaved ideal shanshui city (Han 2015a).

Cultural landscape and the Western environmental philosophy of culture-nature relationship embedded in the World Heritage provide a new environmental ethics for China to transcend its historical cultural limitations. It has impeded the country from recognising the values of the living agricultural landscapes, ordinary landscapes, indigenous landscapes; and conducting nationwide protected landscape system and achieving long-term objectives regarding sustainable land use. The transition of the perspective of nature will be essential to recognise the intrinsic value of nature while maintaining the traditional Chinese humanistic instrumental concerns. Rural landscape conservation and sustainable land use are also key in realising Sustainable Development Goals for a large population base and limited natural resources.

\section{Summary and Further Thinking}

By reviewing the history of the nature-related World Heritage conservation in China, we can clearly see its development and its impact on the country. Conversely, we can see China's contribution and inspiration to the World Heritage by turning from natural conservation to cultural landscape. The history illustrates that everything is dynamically evolving. Both China and the World Heritage are learning from each other. It is important to strengthen international communication, exchanges, and the cultural inclusiveness in the World Heritage.

China has outstanding cultural landscapes, great potential contribution to the region and the WHCL. It has the creativity in digital cultural landscape conservation with the use of new technology. However, it still lacks systematic landscape conservation in terms of value research, categorisation, and therefore, a lack of national protected landscape system, legislation, policies and regulation.

It is especially worrying that the national protected system of Scenic and Historic Interest Areas, which is characterised by significant cultural landscape values, has been moved under the Department of Natural Resource in the latest national institutional adjustments in May 2018. While the international society is turning to cultural landscapes for the integrity of culture and nature, China is creating a new National Park system where nature is most strictly protected, and wilderness is preferred. Although it is worth celebrating that China is becoming aware of the intrinsic scientific values of nature, there is a danger in moving away from its civilisation and humanistic cultural tradition. The Scenic and Historic Interest Areas is now at the edge of an ambiguous position as there is no such a State Department to deal with heritage conservation across culture and nature. China could be inspired by the European Landscape Convention to establish (1) a crosssector cultural landscape protection mechanism, and (2) a legal status of cultural landscape conservation so as to safeguard the conservation and sustainable development of Cultural Landscape from laws and institutions.

The wisdom of culture and nature is of key significance for the sustainability of human society on the earth for future. 'A culture is not a thing, but a process. Moreover, culture is politics.' (Duncan 1980) At this point, the protection of the values of cultural landscape must rise to the political level and social level, as part of the national and international strategy and policy in order to achieve the United Nation's Sustainable Development Goals. In this sense, the cultural landscape is a revolutionary thinking functioning as environment philosophy. It deals with the attitude and practice of the relationship between human and nature, giving high priority to a 'deep cultural diversity' (Naess 2003). After all, the eternal goal is not only to live intelligently and healthily, but also to live in spiritual poetry together with all other forms of life (Han 2016).

\section{Notes}

1. The Analects, Book Six: 21.

2. Herb Stovel, 2008, Personal email contact with the author.

3. The author was commissioned to lead this research project from 2010 to 2012 .

4. The International Symposium on the Conservation and Development of Village Cultural Landscapes was held in Guiyang, Guizhou Province, China in October 2008. The symposium was organised by the UNESCO Beijing Office, the National Cultural Heritage Administration, the Guizhou Provincial Department of Culture, Peking University, Tongji University and hosted by the Guizhou Provincial Bureau of Cultural Heritage. The "Proposal on the Conservation and Development of Village Cultural Landscapes (Guiyang Proposal)" was published as the main outcome of the symposium.

5. Ken Taylor, speech in the 'First Urban Forum', Sept. 
2011, Hangzhou, China.

6. General Conference $36 \mathrm{C} / 23$ Item 8.1

7. Ancient City Yangzhou was the leading city for the nomination of the Grand Canal. In 2010, the author was appointed by the Nomination Office of the Grand Canal and the Slender West Lake to undertake the research on the cultural landscape values of the Slender West Lake and its interweaving relationship with city.

8. Feng Han, 'Research on Cultural Landscape Values and the Categorisation of Scenic and Historic Interest Areas', 2012-2015, funded by the Ministry of Housing and Urban-Rural Development of the People's Republic of China (MOHURD).

\section{References}

Berque, Augustin. 1993. "Beyond the Modern Landscape." AA FILES 25.

Chan, Wing Tsit. 1967. "Chinese Theory and Practice, with Special Reference to Humanism." In The Chinese Mind: Essentials of Chinese Philosophy and Culture, edited by Charles A. Moore, 11-30. Honolulu: EastWest Centre Press, University of Hawaii Press.

Chinanews. 2015. “900,000 Historic Villages Disappeared in China in Last 10 Years." Accessed 14 September 2018. http://www.chinanews.com/cul/2015/0719/7414210.shtml

CWHN (China World Heritage Net). 2004. “The Earthly Fairyland: Preservation and Management of Huang Long Scenic and Historic Interest Area." Accessed January 11, 2004. http://www.cwhn.org/news/news. asp?news $=295$

Feng, J. C. 2001. "We are Happily Destroying Our Culture". China Youth. Accessed April 15, 2005. http:// www.booktide.com/news/20011123/200111230007. html

Feng, Youlan. 2004. Zhongguo zhexue jianshi [The Short History of Chinese Philosophy]. Zhengzhou: Henan People's Publish.

Fowler, Peter J. 2001. "Cultural Landscape: Great Concept, Pity about the Phrase." In The Cultural Landscapes: Planning for Sustainable Partnership between People and Place, 64-82. London: ICOMOS-UK.

Fowler, Peter J. 2003a. "World Heritage cultural landscapes, 1992-2002: A Review and Prospect.” In Cultural Landscapes: the Challenges of Conservation. World Heritage Papers 7. Paris: UNESCO World Heritage Centre.

Fowler, Peter J. 2003b. "World Heritage Cultural Landscapes 1992-2002”. World Heritage Papers 6. Paris:
UNESCO World Heritage Centre.

Guo, S. S. 2003. “The Management Investigation of Taishan Scenic and Historic Interest Area". Accessed January 11, 2004. http://www.cnwh.org/news/news. asp? news $=25$

Han, Feng. 2005. “China's New Wilderness”. Landscape Australia 26 (1): 58-60.

Han, Feng. 2006. “The Chinese View of Nature: Tourism in China's Scenic and Historic Interest Areas." PhD diss., Queensland University of Technology.

Han, Feng. 2007. "World Heritage Cultural Landscapes and New International Trends." Chinese Landscape Architecture 23 (11): 18-21.

Han, Feng, ed. 2011a. "Research Report. 2010 UNESCO Project of Conservation and Management of World Heritage sites in China: Lushan World Heritage Cultural Landscape Research.” Beijing: UNESCO Beijing Office.

Han, Feng, ed. 2011b. "Social Survey Report on of Lushan's Cultural Landscape Value Recognition. 2010 UNESCO Project of Conservation and Management of World Heritage sites in China: Lushan World Heritage Cultural Landscape Research.” Beijing: UNESCO Beijing Office.

Han, Feng. 2015a. “The Traditional Chinese View of Nature and Challenges of Urban Development." In Reconnecting the City: The Historic Urban Landscape Approach and the Future of Urban Heritage, edited by Francesco Bandarin and Ron van Oers, 148-159. Chichester: Wiley Blackwell.

Han, Feng. 2015b. "Historic Urban Landscape Research in China: The Slender West Lake in Yangzhou." Historic Environment 27 (1): 68-77.

Han, Feng. 2016. "Landscape Declaration: Connecting Cutlture and Nature." Speech on the Summit of Landscape Architecture Foundation (LAF), June 10-11, 2016, University of Pennsylvania in Philadelphia.

ICOMOS. 1996. "World Heritage List: Lushan." Accessed 14 September 2018. http://whc.unesco.org/en/list/778/ documents/

IUCN. 1996. "World Heritage Nomination-Technical Evaluation Lushan National Park (China).” Accessed 14 September 2018. http://whc.unesco.org/en/list/778/ documents/

IUCN. 2013. "Study on the Application of Criterion VII. Considering Superlative Natural Phenomena and Exceptional Natural Beauty within the World Heritage Convention.” IUCN, Gland: Switzerland.

IUCN and ICOMOS. 2013. "Connecting Practice: 
Defining New Methods and Strategies to Support Nature and Culture through engagement in the World Heritage Convention.” Accessed 14 September 2018. https://www.iucn.org/ru/node/710

Li, X. L. 2017. "Research on the Cultural Landscape Categorization and the Potential WHCLs Values of the National Scenic and Historic Interest Areas." PhD diss., Tongji University.

Lin, Yutang. 1998. The Importance of Living. Beijing: Foreign Language Teaching and Research Press.

Lin, Yutang. 2000. My Country and My People. Beijing: Foreign Language Teaching and Research Press.

Moore, Charles Alexander, ed. 1967. The Chinese Mind. Honolulu: East-West Centre Press.

Naess, Arne. 2003. “The Deep Ecology Movement: Some Philosophical Aspects.” In Environmental Ethics: An Anthology, edited by Light Andrew and Rolston Holmes III, 240-245. Oxford: Wiley Blackwell.

Norberg-Schulz, Christian. 1980. Genius Loci: Towards a Phenomenology of Architecture. London: Academy Editions.

Obi, Koichi. 1989. Zhongguo wenxue zhong suo biaoxian de ziran he ziran guan [Nature and the Attitude towards Nature in Chinese Literature]. Shanghai: Shanghai Ancient Books Publishing House.

O'Hare, Daniel John. 1997. Tourism and Small Coastal Settlements: A Cultural Landscape Approach for Urban Design. Oxford: Oxford Brooks University.

Relph, Edward. 1974. Place and Placelessness. London: Pion.

Relph, Edward. 1987. The Modern Urban Landscape. London: Croom Helm.

Roe, Maggie. 2007. “The European Landscape Convention: a revolution in thinking about 'cultural landscapes." Chinese Landscape Architecture 23 (11): 10-15.

Rössler, Mechtild. 2003. "Linking Nature and Culture, World Heritage Cultural Landscapes.” In World Heritage Papers 7 Cultural Landscapes: the Challenges of Conservation, edited by Paolo Cecarelli and Mechtild Rössler, 10-15. Paris: UNESCO.

Rössler, Mechtild. 2006. "World Heritage cultural landscapes: A UNESCO flagship programme 1992-2006.” Landscape Research 31(4): 333-353.

Sauer, Carl Ortwin. 1925. "The Morphology of Landscape." University of California Publications in Geography 2 (2):19-53. Reprinted in Land and Life: a Selection from the Writings of Carl Ortwin Sauer, 1963, edited by John Leighley. Berkeley: University of California Press. Scazzosi, Lionella. 2018. "Rural Landscape as Heritage:
Reasons for and Implications of 'Principles on Rural Landscape as Heritage' ICOMOS-IFLA 2017." Built Heritage 2 (3): 39-52.

Shan, Jixiang. 2009. Towards the World of Cultural Landscape Heritage. Tianjin: Tianjin Press.

Shen, Zuxiang. 2002. Tourism and Chinese Culture. Beijing: Tourism Education Press.

Smith, Julian. 2010. "Marrying the old with the new in historic urban landscapes." In World Heritage Papers 27 Managing Historic Cities, edited by Ron van Oers and Haraguchi, Sachiko, 45-52. Paris: UNESCO World Heritage Centre.

Taylor, Ken. 2007. "Cultural Landscape and Asian Values: Negotiating a Transition from an International to an Asian Regional Framework." Chinese Landscape Architecture 23 (11): 4-9.

Taylor, Ken. 2015. “Cities as Cultural Landscapes.” In Reconnecting the City. The Historic Urban Landscape Approach and the Future of Urban Heritage, edited by Francesco Bandarin and Ron van Oers, 179-202. Chichester: Wiley Blackwell.

Tuan, Yi Fu. 1974. Topophilia. Englewood Cliffs: PrenticeHall.

UNESCO. 1996. "Decision: CONF 201 VIII.C, Inscription: Lushan National Park (China).” Accessed 14 September 2018. http://whc.unesco.org/en/decisions/2981

UNESCO. 1998. "United Nations Educational, Scientific and Cultural Organization Convention Concerning the Protection of the World Cultural and Natural Heritage." Accessed 14 September 2018. http://101.96.10.63/ whc.unesco.org/archive/1998/whc-98-conf203-5e.pdf

UNESCO. 2018a. "World Heritage List." Accessed 14 September 2018. http://whc.unesco.org/en/ list $/$ ? search $=\& i d \_s i t e s=\& i d \_s t a t e s=\& i d \_s e a r c h$ region=\&id_search_by_synergy_protection=\&id_ search_by_synergy_element $=\&$ search_yearinscribed $=$ $\&$ themes $=4 \&$ criteria_restrication $=\&$ id_keywords $=\&$ ty pe $=\&$ media $=\&$ order $=$ country\&description

UNESCO. 2018b. “Tentative List.” Accessed 14 September 2018. http://whc.unesco.org/en/tentativelists/state $=\mathrm{cn}$

Van Oers, Ron. 2010, "Managing Cities and the Historic Urban Landscape Initiative: An Introduction.” In Managing Historic Cities, World Heritage Papers 27, edited by Ron van Oers, 7-17. Paris: UNESCO World Heritage Centre.

Van Oers, Ron. 2012. “The Concept of Historic Urban Landscape (HUL) and its Relation to Cultural Landscape." Chinese Landscape Architecture 28 (5): 16-18.

Wang, Yi. 1990. Gardens and Chinese Culture. Shanghai: 
Shanghai People's Press.

Yang, Liying, and Zhang, Zhiyi. 2001. Youya de zhongguoren. [The Graceful Chinese]. Shanghai: Xuelin Press.

Yu, Haomin. 2001. Langman de zhongguoren. [The Romantic Chinese]. Shanghai: Xuelin Press.

Zangheri, Luigi. 2007. "Cultural Landscapes and Monuments of Nature." Chinese Landscape Architecture 23 (11): $1-3$.

Zhang, Chao. 2008. You meng ying [Dreamy Shadow]. Beijing: Zhonghua Book Company.

Zhang, J. 2003. "Struggling between Natural and Manmade World." Accessed January 11, 2004. http://www. hn.xinhuanet.com/ptfx/2003-06/05/content_571803. htm

Zhang, Jiaji. 1986. History of Chinese Gardens. Ha'erbing: Heilongjiang People's Publisher.

Zhou, Mingfeng. 1999. Chaoyue yu chaoba. [Exceeding and Transcending]. Chengdu: Sichuan People's Publisher. 